\title{
A case study of an adult learner with ASD and ADHD in an undergraduate online learning environment
}

\author{
Christopher A. Meyers and Richard G. Bagnall \\ Griffith University, Australia
}

\begin{abstract}
The contemporary need for older workers to participate in education and training programs to increase their employability has exposed many of them to learning opportunities involving online learning in higher education. This paper reports research into the issues and experiences of an adult learner with autism spectrum disorder (ASD) and attentiondeficit/hyperactivity disorder (ADHD) engaging in undergraduate online learning. The issues and experiences were identified through the use of inductive, in-depth interpretive phenomenological analysis (IPA), as part of a larger study. The profile of the target student was very different from the other nine participants in the study, and was interpreted as principally related to disorientation within his online learning environment. Three types of disorientation were identified - navigational, contextual, and procedural - each of which presented strategies for its mitigation. The research revealed a significant disjunction between the characteristics of the learner's online learning environment and his learning needs and preferences, which has implications for the design and development of inclusive online learning environments in higher education.
\end{abstract}

\section{Introduction}

This paper presents findings from a case study that was conducted as part of a larger study exploring the issues and experiences of older workers in their engagement with online learning in undergraduate university study in Australia. The larger study was conducted in view of the increasing participation in skills development activities of older workers seeking to retain their position in employment, and of unemployed older workers seeking to improve their employability. The increased participation in such skills development activities is seen, within Australia and other Organisation for Economic Co-operation and Development (OECD) countries, as a response to the imperative for older workers to increase their workforce participation: one of a number of policies designed to address the fiscal pressure brought about by an ageing population (Organisation for Economic Co-operation and Development [OECD], 2006; The Treasury, 2010). For some older workers, the skills development requirements for them to increase their workforce participation may be quite demanding. Although generally being seen as a heterogeneous group with a diverse range of abilities in various areas (Australian Industry Group, 2007), older workers are disproportionately faced with reading, writing, and numeracy difficulties (Australian Bureau of Statistics, 2006). The learning opportunities that have been provided to facilitate the indicated skills development also present barriers to participation or difficulties in engagement for some learners (OECD, 2006). The use of, and reliance on, computer-based online learning environments for the provision of educational programs continues to increase substantially, both within Australia (Department of Education, Employment and Workplace Relations, 2010) and in other developed countries (OECD, 2010).

Difficulties can arise for those older workers who have little experience of, or are novices in, using computers or hypermedia as the major tools of online learning. Older workers, commonly defined in the literature as 45 years of age and older (Bowman \& Kearns, 2007; Lundberg \& Marshallsay, 2007; Tikkanen, 2009), are unlikely to have had contact with computers or hypermedia during the formative years of their education: the widespread use of personal computers in developed nations did not commence until the mid-1980s (Taylor \& Rose, 2005), and the World Wide Web, the principal means of accessing hypermedia, was not developed until 1989 (Berners-Lee, Cailliau, Groff, \& Pollermann, 1992). Difficulties can also arise from requirements for participation in online assessment activities that are informed by constructivist learning theory (Ally, 2008), as is frequently found at university level (Biggs \& Tang, 2007). These requirements may not be congruent with the learned requirements for participation in assessment activities of prior school and vocational learning environments informed by behavioural or cognitive learning theories (Chappell, 2004). However, while such difficulties have been identified, there is a dearth of research into the specific needs and preferences of older workers in terms of their engagement with online learning, including difficulties with the support they may have received (Bowman \& Kearns, 2007). That dearth of research led the authors to undertake an empirical 
investigation into the experience of online learning from the perspective of older workers themselves. The study involved obtaining qualitative data from ten individual participants, selected from among older workers engaged in online learning in undergraduate university study at an Australian university.

One of the participants in the study was found to have been medically diagnosed with Asperger's syndrome (AS) and attention deficit disorder (ADD) and he attributed a number of difficulties in his engagement with online learning to this condition. AS and ADD have recently been the subject of revised diagnostic criteria in their classification as neurodevelopmental disorders (American Psychiatric Association, 2013). ADD is one of the triad of symptoms that define what is now referred to as attentiondeficit/hyperactivity disorder (ADHD). In the case of AS, several diagnoses (Autistic Disorder, Asperger's Disorder, Pervasive Developmental Disorder Not Otherwise Specified) have now been included in the single diagnosis of autism spectrum disorder (ASD), with AS being a less impairing condition than autism per se. Learning difficulties are not expressly included in the list of diagnostic criteria for either ADHD or ASD. Nevertheless, ADHD, while not considered a learning disability, is widely viewed as a disorder of executive functioning skills with implications for learning (Parker, Hoffman, Sawilowsky, \& Rolands, 2011). Similarly, for ASD, impairments have been documented in the neurophysiological functioning of some individuals, with significant implications for the way in which they learn (Minshew \& Williams, 2008). Prominent psychological constructs of ASD that serve to relate these impairments in neurophysiological functioning to functions and behaviours which may impact on learning ability include: (1) Theory of Mind abilities, where the individual has difficulty determining the thoughts and intentions of others; (2) weak central coherence, where the individual can be remarkably good at attending to detail but have difficulty perceiving the overall picture of something; and (3) impaired executive function, where the individual has difficulty with inhibiting responses, working memory, and using new strategies (Attwood, 2008; Gobbo \& Shmulsky, 2014; Minshew \& Williams, 2008).

While the research was not focussed specifically on learners with learning difficulties, this paper seeks to articulate the atypical experiences of this one participant, together with a methodologically-based interpretation as a way of drawing practitioners' and other researchers' attention to the learning experiences of this subject. The paper should serve as a valuable way of sensitising readers to potential learning difficulties in the online learning context and providing some pointers to the online learning needs and preferences of older workers with similar conditions. The next section of the paper outlines the methodology used in the study. The following section introduces the subject participant and describes his experiences of working in an online learning environment. His strategies to mitigate the problems encountered in that environment are then presented, before discussing these findings in the context of the research literature to date. The paper then draws out the indicated conclusions from the study.

\section{Methodology}

The focus of the study on the issues and experiences of older workers in online learning called for a qualitative orientation, which is used where a problem or issue needs to be explored (Creswell, 2007; Merriam, 2009). Within that orientation, the research study can be broadly classified as interpretive qualitative research, which recognises the interpretive role of the researcher as an interpreter of data (Creswell, 2007). A social constructivist inquiry paradigm was assumed, where individuals are seen as seeking to understand the world in which they live and work, through developing subjective meanings of their experiences (Creswell, 2007). A phenomenological approach was considered to be most suitable as a way of directly addressing the research question. The notion of phenomenology here is that of obtaining experiential information from a number of individuals who have experienced a phenomenon, with a view to understanding and articulating their common or shared experiences (Creswell, 2007). Such an approach aims to achieve a rigorous and unbiased study of things as they appear, in order to arrive at an essential understanding of human consciousness and experience (Dowling, 2007).

Within the phenomenological approach, the interpretive phenomenological analysis (IPA) framework of Smith and colleagues (Reid, Flowers, \& Larkin, 2005; Smith, Flowers, \& Larkin, 2009; Smith \& Osborn, 2008) was chosen for its strong philosophical and empirical grounding and its clearly articulated framework for researching the experiences of others in areas where very little is yet known. IPA is said to be informed by scholarship from three key areas of epistemology: phenomenology as an approach to the study of experience, hermeneutics as the theory of interpretation, and idiography as being concerned with 
single cases (Smith et al., 2009). It is thus concerned with the detailed examination of individual experience, such as that of older workers' engagement with online learning environments, in a way that, as far as possible, enables the experiences to be expressed phenomenologically.

The study participants were selected following a call for volunteers from the mixed-age student population enrolled in the undergraduate study of adult and vocational education at an Australian university. Five men and five women, not less than 45 years of age, were chosen as the first eligible volunteers in each category. Data were collected from each participant through two one-on-one semistructured interviews, each interview including approximately 60 minutes of conversation. A series of open-ended questions, determined to a large extent by a prepared interview schedule, were used to open conversation with each participant, with the intention of understanding all facets of the research question. A digital audio recorder was used to record the interviews for subsequently downloading to computer. A verbatim transcription was produced by the researcher (the lead author) and the textual data were transferred to a flat-file database to assist with data analysis through the generation of reports and data processing through filtering and sorting. Analysis of the interview transcripts through the IPA framework was guided by the works of King and Horrocks (2010), Smith et al. (2009), and Smith and Osborn (2008).

The quality of the study was guided by Smith et al. (2009) who refer to the work of Yardley (2000, 2008) in presenting general guidelines for assessing the quality of qualitative research. Yardley (2000) suggests four criteria of good qualitative research: (1) sensitivity to context, (2) commitment and rigor, (3) transparency and coherence, and (4) impact and importance. The most notable strategy used in the application of these criteria to the conduct of this study was the use of an independent audit, contributing to the validity of the study. An independent audit requires the data to be filed in a way that enables another person to follow the chain of evidence, where "a coherent chain of arguments runs from the initial raw data to the final write-up” (Smith et al., 2009, p. 183). As for other IPA studies, the value of the study was "in terms of theoretical transferability rather than empirical generalisability. In this case, the reader makes links between the analysis in an IPA study, their own personal and professional experience, and the claims in the extant literature” (Smith et al., 2009, pp. 50-51).

The idiographic approach of IPA gave rise to diverse conceptualisations of online learning among the participants. One of the male participants in the study, Jeffrey (a pseudonym), had been medically diagnosed with ADD and Asperger's syndrome, to which he attributed a number of difficulties in his engagement with online learning. These difficulties were significantly different from those of the other participants, principally in terms of the magnitude and extent of the disorientation he experienced, and provide the basis of this paper. The data gathering and analysis stages of the research were undertaken by the researcher in a manner consistent with the concept of 'bracketing' in phenomenological research: "the resolve to set aside theories, research presuppositions, ready-made interpretations, etc., in order to reveal engaged, lived experience” (Ashworth, 1996, p. 1). As such, the researcher did not intentionally engage, at these stages, with the literature regarding older workers in online learning, or more specifically, with the impact of ASD and ADHD on the learning of this participant.

\section{Jeffrey's experiences}

Jeffrey, aged 51, completed his secondary education to year 10 - secondary schooling in Australia being to year 12 - while in a remedial reading class. He indicated that he had not believed that he possessed the ability to undertake the remainder of his secondary education. He then worked as a storeman and, in later years, completed certificate- and diploma-level qualifications in civil engineering drafting, subsequently working as a building designer. In his late 40s, he moved to a teaching role at a technical college and completed certificate-level qualifications in training and assessment. At the time of the research study, he was undertaking undergraduate study towards a professional degree program in adult and vocational education. He reported that he had started using computers in the early 1980s and the Web in the late 1990s, when he was in his late-30s, and that he currently accessed the Web through both a laptop computer and a smart phone. He described his online learning as involving access to the university learning management system and use of the university library, Google advanced search and e-mail, but not involving discussion boards or forums.

During the interviews, Jeffrey provided brief descriptions and occasionally extended narratives to convey an understanding of the nature of his engagement with online learning. His responses centred around the 
difficulties he had experienced in accessing hypermedia-based resources and aligning with procedural expectations in a constructivist learning environment. These difficulties were identified by him as being, to a large extent, a function of his ASD and ADHD. Jeffrey's experiences of online learning were typical of the older worker participants in the study in some respects and significantly atypical in others. They were typical in their recognition that online learning enabled flexible learning opportunities in terms of both time and location, and in their adverse reactions to the use of computer technology. His experiences were most notably atypical in the high levels of disorientation that he reported. Disorientation is taken here as Jeffrey losing his sense of direction, as not having the cognitive ability to orient himself in his learning environment:

If I've got too many links that don't give me a clear direction of where I'm going, then I really don't know if I'm wasting my time filling in, or working on the correct aspect of something. (Jeffrey, 18 June, 2012, p. 10)

The extent of this disorientation was reported to be so pronounced at times that he developed a sense of being lost:

Getting lost online would probably be the worst [aspect of online learning], where you're just going round, and not knowing, having no idea where I'm going or what I'm doing, other than just trying to find links that may, and it's just a process of elimination: "Do I try this link? Oh! Okay! Lost.” (Jeffrey, 18 June, 2012, p. 14)

Jeffrey described his condition as being the source of the disorientation he experienced in his online learning environment:

I do have ADD and Asperger's, and one of the things with that is the tunnel vision effect. I get so absorbed in something that I lose all focus. And that's where, particularly having ADD and Asperger's, the mapping, the neurological, the mental mapping of stuff, means that it's easier to get lost in a maze. ... To find something, you get lost in a maze of links. (Jeffrey, 8 June, 2012, p. 5)

The high levels of disorientation reported by Jeffrey in describing his experiences of online learning occupied most of the interview conversations. While experiences of disorientation were not uncommon among other participants in the study, Jeffrey's experiences of disorientation were unique in terms of their extent and magnitude. They inhibited his engagement with learning in some instances, and entirely prevented it in others. His disorientation was interpreted as being multidimensional across three discrete dimensions: navigational, contextual, and procedural disorientation as articulated in the following sections.

\section{Navigational disorientation}

Navigational disorientation identifies difficulty in navigating hypermedia. It arose in Jeffrey's attempts to select hypermedia links, when he encountered multiple opportunities in the choice of these links in Web navigation tasks. It took the form of being at a loss as to which direction to take, occasionally culminating in a sense of being lost.

He commenced one narration by describing a situation where he was exposed to multiple opportunities to navigate links, resulting in experiences of navigational disorientation:

You start following a link, and it takes you to a page with a paragraph and half a dozen links, that takes you to another page with a paragraph of information, that takes you to half a dozen other links. ... So, it ends up like a spider web, and a maze, where you've got no idea where you're going, or the rationale. (Jeffrey, 8 June, 2012, p. 1)

The situation resulted in an acute sense of being lost, to the extent that he abandoned the task. "I started following that, and ended up so lost that I had no idea where I was in the system, where I was going, etcetera. ... So, I ended up just bailing out, and: 'Forget about that!' ” (Jeffrey, 8 June, 2012, p. 1). 
Jeffrey related numerous such experiences, the most significant one through an extensive narrative regarding the process of university enrolment. He described having spent many hours, prior to his first semester, attempting to enrol online in the university’s courses, and finally abandoning the task:

It took, I spent five and a half, it's either five and a half or five and three quarter, hours trying to enrol at [the university]. And, that was spread over two or three days, and combined e-mails and phone calls, to attempt to enrol. ... And, in the end, someone else enrolled me. (Jeffrey, 8 June, 2012, p. 1)

Once again, his navigational disorientation was precipitated by multiple opportunities in the choice of hypermedia links:

With the [university] enrolment, the big problem was that it was circular, in that you followed one set of links and you end up back where you started. And, you try following other sets of links, and you end up back where you started. ... [In regard to online learning,] trying to find and navigate through Web pages is probably the biggest issue. (Jeffrey, 8 June, 2012, p. 1)

\section{Contextual disorientation}

Contextual disorientation identifies difficulty in placing hypermedia-based information in context. It arose in Jeffrey's attempts to place learning resources in context, when he encountered multiple opportunities to attribute value, relevance, or validity to these resources. It took the form of being at a loss in determining value or validity, occasionally resulting in a lack of confidence in his cognitive abilities.

In reporting his experiences of attributing value to hypermedia-based resources, he often made use of terms that implied a lack of confidence, which he reported was due to an inability to place resources in context when faced with multiple opportunities in the hypermedia environment:

It's a case of confidence. I don't necessarily have a lot of confidence in online learning. ... And, because then, there are so many links, it reduces my confidence in the documentation that I come across. Because, I may be filling out a form ... But, if I'm filling in the wrong form, I'm wasting my time. (Jeffrey, 18 June, 2012, p. 10)

In a narration about determining the value of hypermedia-based resources to his learning, Jeffrey also described a lack of confidence or assuredness regarding the resources he encountered online, which he reported was due to a lack of direction or orientation:

So, online learning doesn't give you the same degree of confidence that face-to-face learning does. ... Because, in face-to-face learning, I guess I'm trusting that the instructor has got the right direction so that I can then follow that, and work with it. Whereas, online, there is no one to ask. (Jeffrey, 18 June, 2012, p. 10)

He also described instances of an inability to place resources in context when seeking to determine the relevance of the resources to the topic of his learning.

"So, although it's an authoritative Web page, and it's valid for the reason that [the] Web page was set up, it’s invalid and irrelevant, for my own learning” (Jeffrey, 18 June, 2012, p. 11).

In summarising numerous such instances where he experienced disorientation in placing hypermediabased resources in context, Jeffrey concluded that

"the terminology, the jargon, metaphors, lines of thought, are all open for reinterpretation, or misinterpretation” (Jeffrey, 18 June, 2012, p. 18).

\section{Procedural disorientation}

Procedural disorientation identifies difficulty in aligning with procedural expectations. It arose in Jeffrey's attempts to align his learning and assessment activities with procedural expectations, when he encountered multiple opportunities in the choice of these activities in his online learning environment. It 
took the form of being at a loss as to which learning or assessment activity to undertake, occasionally resulting in a sense of confusion.

When questioned about the support he received in his online learning, he reported experiencing a sense of isolation.

“Generally, you doesn't [sic]. It’s too isolated. It lacks the personal contact at all” (Jeffrey, 18 June, 2012, p. 19).

He proceeded to relate how, within this isolation, he could not comprehend the correct procedure, a sense of confusion when faced with multiple opportunities in the choice of learning and assessment activities:

So, you're stumbling around in the dark, to start off with. And then, you're going along. So, really, you've got, and that's one of the things that is hard, I guess, there is no real ... Because there's no feedback, etcetera, as you're working, you really don't know if you're, how well you're doing, if you're doing the right thing, if you're going in the right direction. (Jeffrey, 18 June, 2012, p. 19)

He subsequently concluded that the direction that was provided following assessment came too late to address his learning needs:

So, the only time you really get that sort of feedback is when you actually send in the assessment, and then wait to get it marked, to see: "Oh! Yeah! I really was going in the right direction.” So, it’s a bit of hit and miss. (Jeffrey, 18 June, 2012, p. 19)

\section{Dimensions of disorientation}

The foregoing three categories of disorientation - navigational, contextual, and procedural - were interpreted as dimensions of disorientation, where the notion of dimensions points to the fact that each category of experience did not exist in isolation but was an aspect of a common experience, a multidimensional disorientation extending across various situations. Each dimension is grounded in a distinctive aspect of the experience of online pedagogy. Navigational disorientation takes the form of being at a loss as to which direction to take. It arose from difficulty in navigating hypermedia links: of facing multiple opportunities in the choice of these links in a Web navigation task. Contextual disorientation takes the form of being at a loss in determining value or validity. It arose from difficulty in placing hypermedia-based resources in context: of facing multiple opportunities in attributing value, relevance, or validity to these resources. Procedural disorientation takes the form of being at a loss as to which learning or assessment activity to undertake. It arose from Jeffrey's difficulty in aligning his learning and assessment activities with procedural expectations: of facing multiple opportunities in the choice of these activities in the online learning environment. The experiences of disorientation, when conjoined, signalled a significant disjunction between Jeffrey's learning needs as an adult learner with ASD and ADHD and the provisions of his undergraduate learning environment. Jeffrey's experiences of navigational disorientation were similarly reported by eight of the other participants, although to a lesser degree and extent, while his reported experiences of contextual and procedural disorientation were unique. This concept of dimensions of disorientation is seen as being an original contribution to the field which emerged from the inductive nature of the study.

\section{Mitigating the impact of disorientation}

The conversations with Jeffrey were principally concerned with the reactions he experienced to online learning. However, as an articulate adult learner and as a student within a university school of education, he was able to identify issues that he encountered in his learning environment and to reflect on strategies that may be used to address those issues. In particular, the conversations contributed to an understanding of a number of situations where pedagogically-informed practice might be adjusted to support him in his learning, through mitigating the impact of his multidimensional disorientation. These situations are outlined here under the three types of disorientation identified above.

\section{Mitigating the impact of navigational disorientation}

Jeffrey related a number of situations in which he believed the potential for navigational disorientation 
had been avoided or mitigated. The most notable situations were where the Web design incorporated the use of dynamic elements, enabling the display of large amounts of information on the one Web page.

"It had pages of information, in that, when I say pages of information, it wasn't individual Web pages of information, but individual, multiple text pages, within one Web page” (Jeffrey, 8 June, 2012, p. 1).

Information was thus made available sequentially through dynamic elements enabling the expansion and collapse of list items, thus removing the multiple opportunities in the choice of hypermedia links to further information:

So, you can start reading at the top and keep on reading down through, through the article. So, the equivalent of opening, opening up a book, or a booklet, or whatever, where you've got a whole heap of text. ... So, it avoided the common Internet trap, of having very little information and a lot of links. And that I found very helpful. (Jeffrey, 8 June, 2012, p. 1)

As a result, Jeffrey’s potential for navigational disorientation was avoided:

It gave me a clear direction. And each page then told you that it was going to the next page. And then, from there, you can go back. And it gave a clear indication of how the two Web pages related to each other. And you could then follow a path through it. (Jeffrey, 8 June, 2012, p. 2)

He also reported situations where he had been able to devise strategies himself to avoid or mitigate his potential for navigational disorientation.

"I know the ADD and Asperger's is there, but I can build techniques, personal tricks, different lines of thought, to help me work through different situations” (Jeffrey, 8 June, 2012, p. 6).

One of the strategies was to avoid, where possible, the use of hypermedia-based resources that had little information relative to the number of links. In other words, the strategy involved purposefully selecting Web pages with a low density of links to information.

“So, for me, when I'm looking at online learning, if there's a lot of Web pages with very little information and a lot of links, unless it looks specifically relevant, I will avoid it” (Jeffrey, 8 June, 2012, p. 2).

This strategy, however, was implied to have limited use in that the potential for disorientation was only mitigated through avoiding the use of resources which incorporated multiple links and yet which may have been of value to his learning.

Yet another strategy devised by Jeffrey was the creation of a linear sequence of information, to remove the multiple opportunities inherent in hypermedia environments. He described a process where he would use the copy-and-paste function of a word processor to gather screen-captures to produce a linear wordprocessed document.

"One of the things I often do is ... I'll do a screen-capture, a print-screen, and paste that into a Word document. ... That helps me keep track of where I’ve actually been” (Jeffrey, 8 June, 2012, p. 2).

However, although he had devised and implemented this strategy on numerous occasions, he indicated that it also had limited use.

The two strategies above devised by Jeffrey, the selective use of Web pages with a low density of links and screen-capturing to create a paper-trail, were thus interpreted as being of some, but limited, use. Web page design that removed multiple opportunities in the choice of hypermedia links was thus the only consistently effective factor identified by Jeffrey as mitigating his potential for navigational disorientation.

\section{Mitigating the impact of contextual disorientation}

Jeffrey also reported situations where the potential for contextual disorientation was avoided or mitigated. He spoke of experiences where the placement of content-related learning resources adjacent to one another on a Web page was able to assist in providing context. This was exemplified in his use of online help documentation, where:

A lot of people use that. Sort of similar to browsing the Internet, in that they'll look for a topic, click, and there'll be active links within that, that took you to various places within the one document. Whereas, I will do that for some. (Jeffrey, 18 June, 2012, p. 16) 
He proceeded to relate how having access to the information within one file enabled the various items of information to be viewed in context:

But, if there is a PDF file, I will actually grab that file, put it somewhere else that I can browse through, and scroll through the entire document. Because, I know there's a lot of times where the question I'm asking either won't get an answer, because it's the wrong question, or it'll get a question, get an answer that doesn't fully answer what I'm looking for. But, if I can scroll through the document, then I can find it myself. (Jeffrey, 18 June, 2012, p. 16)

Direct communication with a lecturer or other knowledgeable person was perceived by Jeffrey to be the most effective approach to contextualising the placement of hypermedia-based learning resources through its clarification of relationships and observations as to the value of particular resources. The advice and direction he received from knowledgeable persons thus mitigated the impact of his contextual disorientation:

Quite often, to try and find a phone number, or an e-mail help is very, very difficult. When you can find that, and you can actually get through to a real person, and explain and talk about what it is you're looking for, like you might talk in a class with a lecturer: "This is what I'm trying to do, but I just can't get it to work!” That's when you can get some real help! (Jeffrey, 18 June, 2012, p. 17)

These two factors, Web page design with a considered approach to the placement of learning resources, and communication with a knowledgeable person, were thus identified by Jeffrey as effective factors in mitigating his potential for contextual disorientation.

\section{Mitigating the impact of procedural disorientation}

Jeffrey also related situations in which he believed the potential for procedural disorientation had been avoided or mitigated. In particular, the real-time support during group-based or tutorial learning sessions re-established his confidence and provided direction to his learning and assessment activities. He attributed his lack of confidence, his stumbling around in the dark in his online learning, to a lack of direction from the lecturer.

"So, lack of, lack of leadership. Because a teacher, instructor, a lecturer, etcetera, is there to lead. And, a lack of leadership” (Jeffrey, 18 June, 2012, p. 19).

He proceeded to suggest that signposts in the form of communications from the lecturer were able to mitigate what he perceived as a lack of direction.

"If online learning was combined with good signposts. It could be a lecturer sending out: 'Search this, ah, in regards to this.' So, you've got a direction to go” (Jeffrey, 18 June, 2012, p. 19).

Direct communication with a lecturer or other knowledgeable person in the content area was thus an effective factor identified by Jeffrey as mitigating his potential for procedural disorientation.

\section{Discussion}

The magnitude of Jeffrey's disorientation, leading to an abandonment of learning tasks, and the extent of the disorientation, across multiple dimensions, were unique among the adult learners in the broader study of older worker engagement with online learning and have prompted this paper. The inductive nature of the study investigating Jefffrey's experiences resulted in the identification of three dimensions of disorientation, the recognition of which represents an original contribution to the field, extending our understanding of potential difficulties in learner engagement with online learning, each dimension being grounded in a distinctive aspect of his experience of the online pedagogy. These findings are discussed below in a wider context, notably the literature related to disorientation in hypermedia learning environments, that relates to learning difficulties that may arise for individuals with ASD and ADHD, and literature related to pedagogically-informed practice that might be adjusted to mitigate the potential for disorientation. 


\section{Disorientation in hypermedia learning environments}

Experiences of disorientation or of becoming lost, here reported by Jeffrey, are not infrequently referred to in the academic literature related to online learning environments, but essentially with respect to the navigation of hypermedia (Amadieu, Tricot, \& Marine, 2009; Scheiter \& Gerjets, 2007; Schnotz \& Heiss, 2009). The literature regarding disorientation in hypermedia learning environments centres around the opportunities afforded by user control of non-linear text and other media found in these learning environments and the way in which these opportunities can result in extraneous cognitive load and associated disorientation. For Jeffrey, experiences of disorientation were interpreted as having their origin in situations where he cognitively encountered multiple opportunities in his online learning environment. This interpretation aligns with studies which show that increased navigational opportunity in hypermedia environments increase the possibility of disorientation (Gall \& Hannafin, 1994). However, the severity of Jeffrey's reported experiences indicated that other factors, such as those that may be related to his condition, may have been instrumental in amplifying such disorientation for him.

\section{Disorientation related to ASD and ADHD}

Although the high level of difficulty experienced by Jeffrey cannot be directly attributed to either of his conditions through their diagnostic criteria, the literature notably identifies deficits in Theory of Mind abilities, weak central coherence, and impaired executive function as key constructs in understanding learning difficulties that may arise for individuals with ASD and ADHD. Such constructs point to an understanding of the impact that these conditions may have on the potential for disorientation across aspects of the pedagogical experience. Most notably, weak central coherence and impaired executive function have been associated with deficits in the ability to respond to multiple opportunities in the learning environment. For example, in relation to the construct of weak central coherence, a study of high functioning adolescents and adults with autism found that the capacity to learn and remember deteriorated as the complexity of the information increased, while reducing this complexity, through the provision of tutoring designed to simplify concepts for the learner, mitigate such deterioration (Minshew \& Williams, 2008). A similar example, in relation to the construct of impaired executive function, investigated US college students with ADHD and found that tutoring designed to simplify concepts increased selfregulation and mitigated the impact of impaired executive functioning (Parker et al., 2011).

\section{Mitigating the impact of disorientation}

Jeffrey described situations in his learning environment where his disorientation was less severe, and also situations where he was able to avoid or mitigate the potential for disorientation. However, while, to varying extents, mitigating factors have been individually identified in the literature, no overarching theory has been located which either informs an understanding of, or identifies mitigating factors which may be associated with, Jeffrey's diverse experiences of disorientation. Jeffrey, himself, described a number of situations where pedagogically-informed practice might be adjusted to mitigate the impact of his disorientation. Web page design with a low density of links to information was reported by him to reduce the potential for navigational disorientation. Web page design with the placement of contentrelated learning resources adjacent to one another on a Web page was reported to reduce the potential for contextual disorientation. The strategy developed by Jeffrey of using screen-captures to create a papertrail reduced the potential for navigational disorientation. Most notably, Jeffrey reported that Web page design that removed multiple opportunities in the choice of hypermedia links was the only consistently effective factor mitigating his potential for navigational disorientation. This view aligns with studies which show that a reduction in the number of opportunities, a minimalist design, may be an effective strategy for mitigating disorientation and assisting learning (Wells \& McCrory, 2011). More specifically, Jeffrey reported that the use of dynamic elements, allowing a large amount of information - presented sequentially through the expansion and collapse of list items - to be displayed on one Web page, was most effective in mitigating the potential for navigational disorientation. Such a design, which may be facilitated by the use of JavaScript or similar programming tools, has been shown in previous studies to maintain the content of the Web page in context (Schraefel, Karam, \& Zhao, 2003), which, in turn, has been found to reduce perceived disorientation (Webster \& Ahuja, 2006). Personal communication with a lecturer or other knowledgeable person in the content area was reported by Jeffrey as the most effective way of mitigating the potential for both contextual and procedural disorientation. Scaffolding of learners in online environments through such communication, where both context and direction are provided, has 
been shown to reduce the multiple opportunities in the choice of associated cognitive activities and, as a result, learning activities have been found to become more tractable (Reiser, 2004).

The severity of Jeffrey's disorientation in his online learning environment, however, indicated that the factors that may have been effective in mitigating his disorientation were not readily available to him. There was clearly a disjunction between his online learning needs for reduced opportunities in his online learning environment to mitigate his disorientation, and the delivery of his online learning programs, which seemed to favour the provision of multiple opportunities in the choice of learning resources. That disjunction is unlikely to be a function of the particular programmatic research context, since the openness to choice of study path and learning resources, and the provision of multiple opportunities in those regards, are central features of constructivist approaches to teaching and learning, which are contemporarily strongly argued to be at the core of high quality tertiary-level curriculum (Biggs \& Tang, 2007; Howie \& Bagnall, 2013; Ramsden, 2003). It is precisely those features that led to the severe disorientation experienced by Jeffrey in this study.

Nevertheless, the sort of mitigating factors identified in this study may well point to strategies that could be employed in the design and management of online learning in higher education. Those strategies are suggested from this research project to include: limiting the density of hypermedia links in any one page, screen-capturing to create a paper trail, the contiguous placement of such links, the ready availability of personal online technical support, and direct access to personalised content expertise when required. The unit learning costs of the last two of these strategies, needless to say, tend to be inversely proportional to the course enrolment numbers (Bates, 2005; OECD, 2001) and to be prohibitively expensive for lowenrolment courses. Undoubtedly, further research, if it confirms the findings of this study, will identify further strategies to alleviate the learning difficulties arising from this disjunction.

\section{Conclusion}

This paper describes the quite severely disorienting online learning experiences of an older learner with ASD and ADHD who was unfamiliar with online learning. The disorientation emerged as being multidimensional, experienced across three different dimensions - navigational, contextual, and procedural - and it indicated a significant disjunction between the characteristics of the learner's online learning environment and his learning needs and preferences across diverse fields of his learning. It was also found that the effects of these dimensions of disorientation were mitigated to some extent by factors within the learning environment and by actions taken by the learner. Web page design with a low density of links to information, dynamic elements enabling a large amount of information to be displayed on one Web page, and a strategy developed by the learner using screen-captures to create a paper-trail were found to reduce the potential for navigational disorientation. Web page design with the placement of content-related learning resources adjacent to one another on a Web page was found to mitigate contextual disorientation. Personal communication with a lecturer or other knowledgeable person in the content area was found to mitigate both contextual and procedural disorientation. The study points to the potential for these mitigating factors to be used in instructional design to facilitate alleviation of the disorienting effects of ASD and ADHD. Further research, though, is needed to ascertain the extent to which the findings reported here are reflective of the experiences of other older learners with similar conditions.

\section{References}

Ally, M. (2008). Foundations of educational theory for online learning. In T. Anderson (Ed.), The theory and practice of online learning (2nd ed., pp. 15-44). Athabasca, Canada: Athabasca University.

Amadieu, F., Tricot, A., \& Marine, C. (2009). Exploratory study of relations between prior knowledge, comprehension, disorientation and on-line processes in hypertext. The Ergonomics Open Journal, 2(1), 49-57. http://dx.doi.org/10.2174/1875934300902010049

American Psychiatric Association. (2013). Diagnostic and statistical manual of mental disorders (5th ed.). Arlington, VA: American Psychiatric Publishing.

Ashworth, P. D. (1996). Presuppose nothing! The suspension of assumptions in phenomenological psychological methodology. Journal of Phenomenological Psychology, 27(1), 1-25. http://dx.doi.org/10.1163/156916296X00014

Attwood, T. (2008). The complete guide to Asperger's syndrome. London, England: Jessica Kingsley 
Publishing.

Australian Bureau of Statistics. (2006). Adult literacy and life skills survey, summary results, Australia, 2006 (Cat. No. 4228.0). Retrieved from http://www.abs.gov.au/ausstats/abs@.nsf/mf/4228.0

Australian Industry Group. (2007). Skilling the existing workforce: Background research report. Sydney, Australia: Author.

Bates, A.W. (2005). Technology, e-learning and distance education (2nd ed.). London, England: Routledge.

Berners-Lee, T., Cailliau, R., Groff, J., \& Pollermann, B. (1992). World-Wide Web: The information universe. Electronic Networking, 2(1), 52-58. http://dx.doi.org/10.1108/eb047254

Biggs, J., \& Tang, C. (2007). Teaching for quality learning at university: What the student does (3rd ed.). New York, NY: The Society for Research into Higher Education and Open University Press.

Bowman, K., \& Kearns, P. (2007). E-learning for the mature age worker. Canberra, Australia: Department of Education, Science and Training.

Chappell, C. (2004). Contemporary vocational learning - Changing pedagogy. Proceedings of the 7th Australian Vocational Education and Training Research Association (AVETRA) Conference, Canberra. Nowra, Australia: AVETRA.

Creswell, J. W. (2007). Qualitative inquiry and research design: Choosing among five approaches (2nd ed.). Thousand Oaks, CA: Sage Publications.

Department of Education, Employment and Workplace Relations. (2010). 2010 E-learning benchmarking survey - Final report. Canberra, Australia: Australian Flexible Learning Framework, Department of Education, Employment and Workplace Relations; I \& J Management Services.

Dowling, M. (2007). From Husserl to van Manen. A review of different phenomenological approaches. International Journal of Nursing Studies, 44(1), 131-142. http://dx.doi.org/10.1016/j.ijnurstu.2005.11.026

Gall, J. E., \& Hannafin, M. J. (1994). A framework for the study of hypertext. Instructional Science, 22(3), 207-232. http://dx.doi.org/10.1007/BF00892243

Gobbo, K., \& Shmulsky, S. (2014). Faculty experience with college students with autism spectrum disorders: A qualitative study of challenges and solutions. Focus on Autism and Other Developmental Disabilities, 29(1), 13-22. http://dx.doi.org/10.1177/1088357613504989

Howie, P. C., \& Bagnall, R.G. (2013). A critique of the deep and surface approaches to learning model. Teaching in Higher Education, 18(4), 389-400. http://dx.doi.org/10.1080/13562517.2012.733689

King, N., \& Horrocks, C. (2010). Interviews in qualitative research. London, England: Sage Publications.

Lundberg, D., \& Marshallsay, Z. (2007). Older workers' perspectives on training and retention of older workers. Adelaide, Australia: National Centre for Vocational Education Research.

Merriam, S.B. (2009). Qualitative research: A guide to design and implementation. San Francisco, CA: Jossey-Bass.

Minshew, N. J., \& Williams, D. L. (2008). Brain-behavior connections in autism. In K. D. Buron, \& P. J. Wolfberg (Eds.), Learners on the autism spectrum: Preparing highly qualified educators (pp. 45-65). Shawnee Mission, KS: Autism Asperger Publishing Company.

Organisation for Economic Cooperation and Development. (2001). E-learning in post-secondary education: Trends, issues and policy challenges ahead. A seminar report. Paris, France: Author.

Organisation for Economic Cooperation and Development. (2006). Live longer, work longer: A synthesis report. Paris, France: Author.

Organisation for Economic Cooperation and Development. (2010). Trends shaping education 2010. Paris, France: Author.

Parker, D. R., Hoffman, S. F., Sawilowsky, S., \& Rolands, L. (2011). An examination of the effects of ADHD coaching on university students' executive functioning. Journal of Postsecondary Education and Disability, 24(2), 115-132.

Ramsden, P. (2003). Learning to teach in higher education (2nd ed.). London, England: Routledge Falmer.

Reid, K., Flowers, P., \& Larkin, M. (2005). Exploring lived experience. The Psychologist, 18(1), 20-23.

Reiser, B. J. (2004). Scaffolding complex learning: The mechanisms of structuring and problematizing student work. The Journal of the Learning Sciences, 13(3), 273-304. http://dx.doi.org/10.1207/s15327809jls1303_2

Scheiter, K., \& Gerjets, P. (2007). Learner control in hypermedia environments. Educational Psychology Review, 19(3), 285-307. http://dx.doi.org/10.1007/s10648-007-9046-3

Schnotz, W., \& Heiss, A. (2009) Semantic scaffolds in hypermedia learning environments. Computers in Human Behavior, 25(2), 371-380. http://dx.doi.org/10.1016/j.chb.2008.12.016 
Schraefel, M. C., Karam, M., \& Zhao, S. (2003). mSpace: Interaction design for user-determined, adaptable domain exploration in hypermedia. In AH 2003: Workshop on Adaptive Hypermedia and Adaptive Web Based Systems, Nottingham, UK, August 26-30, 2003 (pp. 217-235). Southampton, England: University of Southampton.

Smith, J. A., Flowers, P., \& Larkin, M. (2009). Interpretative phenomenological analysis: Theory, method and research. London, England: Sage Publications.

Smith, J. A., \& Osborn, M. (2008). Interpretative phenomenological analysis. In J. A. Smith (Ed.), Qualitative psychology - A practical guide to research methods (2nd ed., pp. 53-80). London, England: Sage Publications.

Taylor, T., \& Rose, J. (2005). Bridging the divide: Older learners and new technologies. ICT and older learners. Strategies and case studies. Proceedings of the $8^{\text {th }}$ Australian Vocational Education and Training Research Association (AVETRA) Conference, Brisbane. Nowra, Australia: AVETRA.

The Treasury. (2010). Intergenerational report 2010. (Chapter 4: Ageing pressures and spending, pp. 4569). Barton, Australia: Attorney-General's Department.

Tikkanen, T. (2009). The learning society as a greying society: Perspectives for older workers and lifelong learning. In Cedefop reference series. Modernising vocational education and training, fourth report on vocational training research in Europe: Background report, Volume 2 (pp. 195-238). Luxembourg, Luxembourg: Office for Official Publications of the European Communities.

Webster, J., \& Ahuja J. S. (2006). Enhancing the design of Web navigation systems: The influence of user disorientation on engagement and performance. MIS Quarterly, 30(3), 661-678.

Wells, A. T., \& McCrory, R. (2011). Hypermedia and learning: Contrasting interfaces to hypermedia systems. Computers in Human Behavior, 27(1), 195-202. http://dx.doi.org/10.1016/j.chb.2010.07.036

Yardley, L. (2000). Dilemmas in qualitative health research. Psychology \& Health, 15(2), 215-228. http://dx.doi.org/10.1080/08870440008400302

Yardley, L. (2008). Demonstrating validity in qualitative psychology. In J.A. Smith (Ed.), Qualitative psychology - A practical guide to research methods (2nd ed., pp. 235-251). London, England: Sage Publications.

Corresponding author: Christopher A Meyers, c.meyers@meyers.com.au

Australasian Journal of Educational Technology (C) 2015.

Please cite as: Meyers, C. A. \& Bagnall, R. G. (2015). A case study of an adult learner with ASD and ADHD in an undergraduate online learning environment. Australasian Journal of Educational Technology, 31(2), 208-219. 